\title{
Studi Analisis Optimalisasi Submerged Scraper Chain Conveyor (SSCC) Terhadap Kehandalan Kinerja Boiler PLTU Unit 50
}

\author{
${ }^{1}$ Tijaniyah, ${ }^{2}$ Moh. Bahrudin, ${ }^{3}$ Syandro Cahyo N \\ 1,2,3 Program Studi Teknik Elektro, Fakultas Teknik, Universitas Nurul Jadid \\ ${ }^{1}$ tijaniyah@unuja.ac.id, ${ }^{2}$ udintf06@gmail.com, ${ }^{3}$ syandrocahyo@gmail.com
}

\begin{tabular}{l}
\hline Article Info \\
\hline Article history: \\
Received September $15^{\text {th }}, 2021$ \\
Revised September $21^{\text {th }}, 2021$ \\
Accepted October $13^{\text {th }}, 2021$
\end{tabular}

\section{Keyword:}

Optimization

SSCC analysis

performance reliability

boiler power plant system

\section{ABSTRACT}

SSCC (Submerged Scraper Chain Conveyor) is one of the parts that affect the combustion process in the Unit 50 PLTU Paiton boiler which can generate electricity up to around $650 \mathrm{MW}$. SSCC is used to accommodate combustion materials in the form of deposits from inside the boiler. SSCC is also used as a seal for the furnace and prevents air from entering during draft system in service, by keeping the water level in the SSCC at a certain set point value. Even the SSCC stops operating at full load, the unit will potentially debating. This aims to reduce fuel consumption so that the material from the combustion is not too much. The increase in the volume of bottom ash material can cause several problems such as SSCC trips due to overload and loose chain from the pulley. The local operator checks the condition of the bottom ash material on the SSCC scraper at a certain time manually and reports it to the CCR operator. This will affect the reliability of the SSCC's performance on the boiler. This research approach is qualitative, because this research is descriptive and tends to use data analysis. The theoretical basis is used as a guide so that the author can focus on analyzing the data according to the facts in the field. From the results of data analysis applied in the field, it shows that the use of a protection system is the first step in dealing with an incident in the field and to secure other equipment. Based on the work system implemented in the field, namely the SSCC system which was previously operated manually, then changed to auto / easier to operate, it proves that it will create an effective and efficient work system during the unit's operation, thus facilitating the work of operators in the field, as well as improving the quality of equipment which is local. In addition, the development of proposals / ideas that can build a better work system is very much needed in the PLTU generating unit.

Copyright (ㅇ 2021 Jurnal JEETech. All rights reserved.

Corresponding Author: Tijaniyah

Program Studi Teknik Elektro, Fakultas Teknik, Universitas Nurul Jadid

Address: Jl. PP Nurul Jadid, Dusun Tj. Lor, Karanganyar, Kec. Paiton, Kabupaten Probolinggo, Jawa Timur 67291

Email: tijaniyah@unuja.ac.id

\begin{abstract}
Abstrak - SSCC (Submerged Scraper Chain Conveyor) merupakan salah satu bagian yang berpengaruh terhadap proses pembakaran di dalam boiler Unit 50 PLTU Paiton yang dapat menghasilkan daya listrik hingga mencapai sekitar 650MW. SSCC digunakan untuk menampung material hasil pembakaran berupa deposit dari dalam boiler. SSCC juga digunakan sebagai seal dari furnace dan mencegah udara masuk pada saat draft system inservice, dengan cara menjaga level air di SSCC pada nilai set point tertentu. Apabila SSCC berhenti beroperasi pada beban penuh, maka unit akan berpotensi turun beban (derating). Hal ini bertujuan untuk mengurangi konsumsi bahan bakar agar material hasil pembakaran juga tidak terlalu banyak. Peningkatan volume material bottom ash dapat menyebabkan beberapa permasalahan seperti SSCC trip karena overload dan lepasnya rantai dari pulley. Operator lokal mengecek kondisi material bottom ash pada scraper SSCC di rentang waktu tertentu secara manual dan melaporkannya pada operator CCR. Hal ini akan mempengaruhi kehandalan dari kinerja SSCC terhadap
\end{abstract}

boiler. Pendekatan penelitian ini adalah kualitatif, karena dalam penelitian ini bersifat deskriptif dan cenderung menggunakan analisis data. Landasan teori dimanfaatkan sebagai pemandu agar penulis dapat fokus menganalisis data sesuai dengan fakta di lapangan. Dari hasil analisis data yang diterapkan di lapangan menunjukkan bahwa penggunaan sistem proteksi merupakan langkah awal dalam menangani sebuah kejadian di lapangan serta untuk mengamankan equipment yang lain. Berdasarkan sistem kerja yang diterapkan di lapangan yakni sistem SSCC yang sebelumnya dioperasikan secara manual, kemudian diubah menjadi auto / lebih mudah dioperasikan membuktikan bahwa akan menciptakan sistem kerja yang efektif dan efisien selama unit beroperasi, sehingga memudahkan pekerjaan dari operator di lapangan, serta meningkatkan kualitas equipment yang berada di lokal. Selain itu, perkembangan usulan / ide yang dapat membangun sistem kerja menjadi lebih baik sangat diperlukan di unit pembangkit PLTU. 


\section{PENDAHULUAN}

Pada Pembangkit Listrik Tenaga Uap unit 50 yang terletak di wilayah paiton kabupaten probolinggo ini menghasilkan daya 650MW. Salah satu bagian yang berpengaruh terhadap proses pembakaran di dalam boiler Unit 50 PLTU Paiton ini yaitu terdapat sebuah equipment dinamakan SSCC (Submerged Scraper Chain Conveyor). SSCC digunakan untuk menampung material hasil pembakaran berupa deposit dari dalam boiler. Material hasil pembakaran ini dinamakan dengan bottom ash [2]. Bottom ash harus selalu di buang agar tidak menumpuk dan mengganggu operasi dan kinerja dari boiler. SSCC mengirim bottom ash menuju bottom ash conveyor yang selanjutnya dimasukkan dan di tampung di bottom ash silo. Dari bottom ash silo, material bottom ash secara periodik akan di unload serta dibuang di disposal area menggunakan dump truck. SSCC merupakan equipment yang penting karena SSCC harus selalu beroperasi untuk membuang material bottom ash. Apabila SSCC berhenti beroperasi pada beban penuh, maka unit akan berpotensi turun beban (derating). Hal ini bertujuan untuk mengurangi konsumsi bahan bakar agar material hasil pembakaran juga tidak terlalu banyak. Dengan diturunkannya beban ini, maka unit akan mengalami kerugian tiap waktunya [1].

Penggunaan batubara kalori rendah menyebabkan volume material bottom ash meningkat sehingga menambah beban kerja dari SSCC [3]. Peningkatan volume material bottom ash dapat menyebabkan beberapa permasalahan seperti SSCC trip karena overload dan lepasnya rantai dari pulley. SSCC merupakan peralatan yang harus beroperasi 24 jam bersamaan dengan operasi boiler yang terus menerus menghasilkan material bottom ash, sehingga gangguan pada SSCC akan sangat mempengaruhi kehandalan operasional unit. Upaya yang telah dilakukan bidang produksi adalah peningkatan intensitas patrol check dan pengendalian pola shootblower oleh operator Center Control Room (CCR). Operator local mengecek kondisi material bottom ash pada scraper SSCC di rentang waktu tertentu secara manual dan melaporkannya pada operator CCR. SSCC system juga digunakan sebagai seal dari furnace dan mencegah udara masuk pada saat draft system inservice, dengan cara menjaga level air di SSCC pada nilai set point [1]. Salah satu media penampung air untuk meng-sealing SSCC adalah sump pit. Hal ini perlu diperhatikan sehingga level air dalam sump pit harus dapat terkontrol sesuai dengan set point. Pada awalnya level sensor pada sump pit menggunkan sensor level berupa stick, dan beberapa waktu yang lalu sensor ini tidak dapat mengontrol level air. Hal ini diindikasikan dengan make-up water SSCC masih dalam keadaan terbuka, sehingga tetap mengisi air pada SSCC walaupun level air di sump pit sudah tinggi. Jika sensor level tersebut tidak dapat bekerja dengan baik akan mempengaruhi kehandalan pada sistem SSCC seperti adanya udara yang masuk kedalam boiler melewati SSCC, dikarenakan level water untuk men-sealing SSCC tidak cukup, sehingga mengakibatkan unit trip dikarenakan pressure dari boiler kurang dari set point yang diinginkan. Kolam SSCC (SSCC sump) merupakan media yang digunakan untuk menampung air dan lumpur (sludge/wet ash) yang berasal dari tumpahan (overflow) SSCC. Desain kolam SSCC terdiri dari tiga kopartemen, yakni: kompartemen sludge pump, kompartemen sump pump dan kompartemen pyrites sluice pump. Tumpahan air yang bercampur dengan lumpur (sludge/wet ash) dari SSCC masuk ke kompartemen sludge pump. Pada kompartemen tersebut diharapkan lumpur (sludge/wet ash) mengendap, sehingga air yang menuju ke 
kompartemen berikutnya (kompartemen sump pump dan pyrites sluice pump) sudah terbebas dari lumpur (sludge/wet ash). Seringkali lumpur (sludge/wet ash) tidak sepenuhnya mengendap di kompartemen sludge pump sehingga terikut ke kompartemen berikutnya dan mengendap. Volume endapan lumpur tersebut makin hari makin meningkat. Peningkatan endapan lumpur memicu timbulnya berbagai masalah antara lain frekuensi pembersihan sludge di SSCC sump yang semakin sering. Sensor level SSCC sump (pelampung) pada saat terjadi perubahan level air sering terganggu untuk naik/turun. Foot valve pyrites sluice pump sering stuck dan foot valve SSCC recirculation pump sering terjadi buntu. Untuk itu perlu untuk menghindari gangguan pada SSCC agar tetap dapat menjaga kehandalan operasional pada unit..

\section{METODE PENELITIAN}

\section{A. Metode}

Pendekatan penelitian ini adalah kualitatif, karena dalam penelitian ini bersifat deskriptif dan cenderung menggunakan analisis data. Landasan teori dimanfaatkan sebagai pemandu agar penulis dapat fokus menganalisis data sesuai dengan fakta di lapangan. Dalam penelitian ini, proses pengumpulan data dilakukan di PT. YTL Jawa Timur dan observasi dilakukan pada SSCC unit 50. Penelitian ini bertujuan untuk mengetahui kondisi nyata dari SSCC yang digunakan pada PLTU Paiton unit 50. Sumber data yang digunakan dalam penelitian ini adalah (1) hasil analisis pada sistem SSCC yang sudah diterapkan dan yang masih sebagai rekomendasi untuk diterapkan di PLTU Paiton unit 50, (2) dokumentasi pada sistem SSCC, (3) Interview langsung kepada pihak engineering sebagai responsibility penerapan project di lapangan.

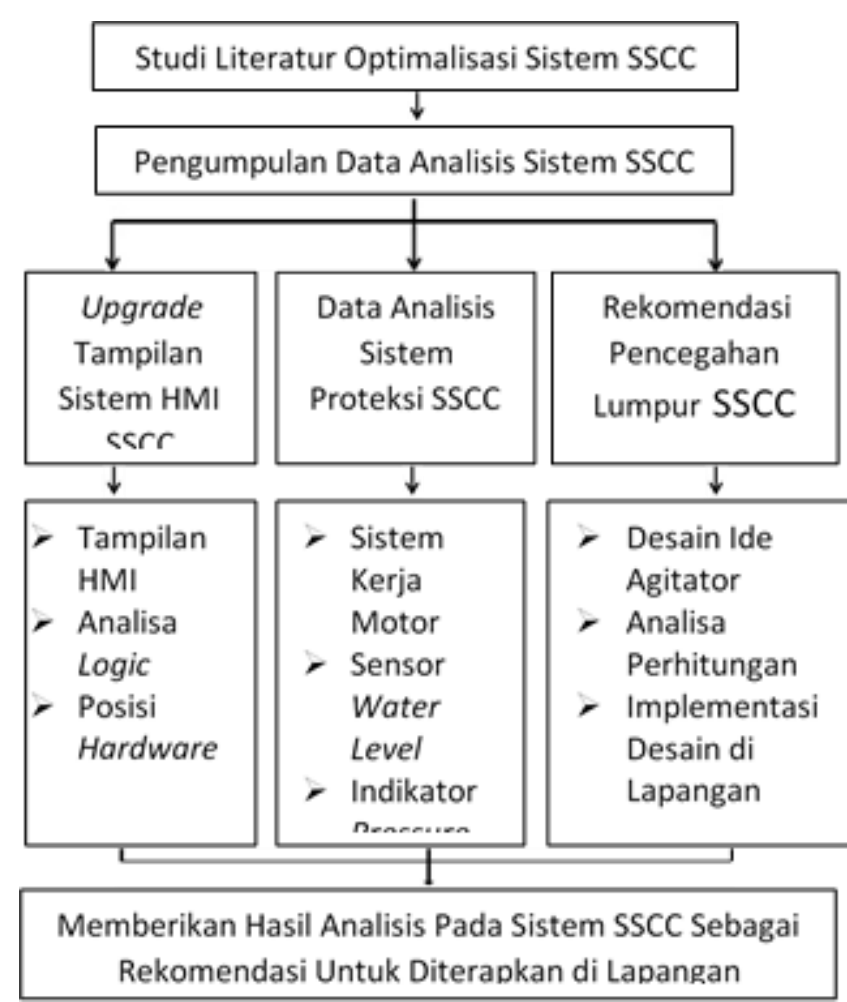

Gambar 1. Kerangka Penelitian

Instrumen utama dalam penelitian ini adalah peneliti. Peneliti merupakan pihak yang mengumpulkan data dan mengolah hasil pengumpulan data. Peneliti melakukan pengumpulan data, pengolahan data, menganalisis data, serta melakukan perencanaan pada proses penelitian. Peranan peneliti diperlukan dalam proses pengumpulan data dan pengolahan data. Menurut Suharsaputra, instrumen penelitian menempati kedudukan penting dalam suatu penelitian karena keberhasilan suatu penelitian dipengaruhi oleh instrumen yang digunakan. Data diperoleh dari dokumen yang ada di ruang document control PT. YTL Jawa Timur. 


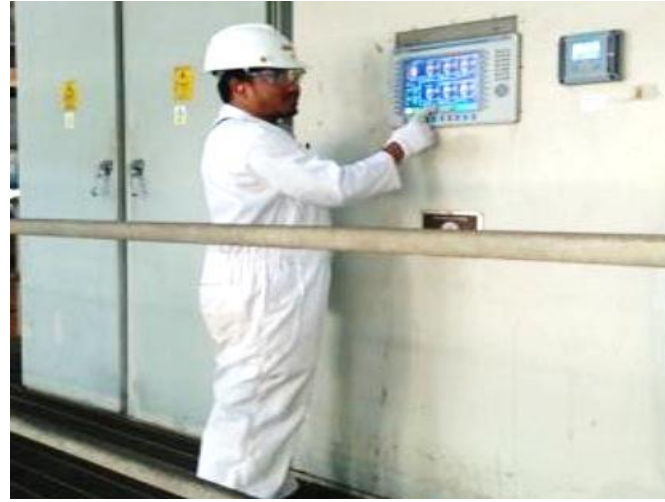

Gambar 2. Pengoperasian sebelum di upgrade

Tampilan HMI sebelum di upgrade dan masih dioperasikan secara manual oleh operator lokal dengan menekan tombol touchscreen di lapangan.

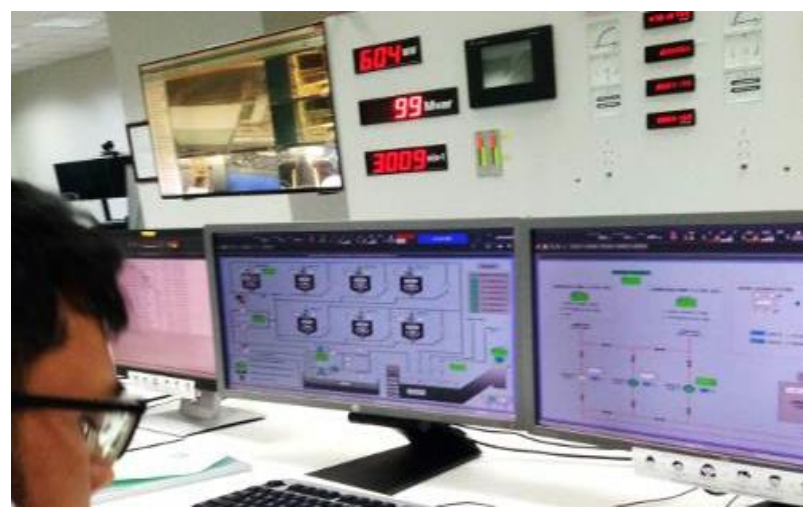

Gambar 3. Pengoperasian sesudah di upgrade

Tampilan HMI sesudah di upgrade dan dioperasikan secara auto oleh unit control yang ada di CCR (Central Control Room). Tampilan HMI tersebut digunakan sebagai support kinerja pada sistem SSCC. Transport pyrites system merupakan proses meremove reject dari pulverizer yang ada di dalam pyrite hopper menuju kedalam SSCC. Reject pulverizer tersebut harus ditransport minimal 2 jam sekali agar pyrite hopper dapat terjaga optimal saat beroperasi. Sebelum adanya tampilan HMI tersebut, operator lokal harus mengoperasikan manual dengan menekan tombol start di lokal. Kendalanya adalah operator tidak bisa standby di lokal tepat waktu dalam mengoperasikannya, dikarenakan pekerjaan lain yang tidak bisa ditinggalkan, sehingga pengoperasian sistem transport hanya tergantung pada kesediaan waktu operator lokal. Akibatnya hopper pulverizer akan terjadi penumpukkan reject dan akan mengganggu kerja dari sistem pulverizer selama proses berlangsung.

\section{B. Analisa Metode Menggunakan Agitator}

SSCC system juga digunakan sebagai seal dari furnace dan mencegah udara masuk pada saat draft system inservice, dengan cara menjaga level air di SSCC pada nilai set point. Salah satu media penampung air untuk meng-sealing SSCC adalah sump pit. Hal ini perlu diperhatikan sehingga level air dalam sump pit harus dapat terkontrol sesuai dengan set point. Pada awalnya level sensor pada sump pit menggunkan sensor level berupa stick, dan beberapa waktu yang lalu sensor ini tidak dapat mengontrol level air. Hal ini diindikasikan dengan make-up water SSCC masih dalam keadaan terbuka, sehingga tetap mengisi air pada SSCC walaupun level air di sump pit sudah tinggi. Jika sensor level tersebut tidak dapat bekerja dengan baik akan mempengaruhi kehandalan pada sistem SSCC seperti adanya udara yang masuk kedalam boiler melewati SSCC.

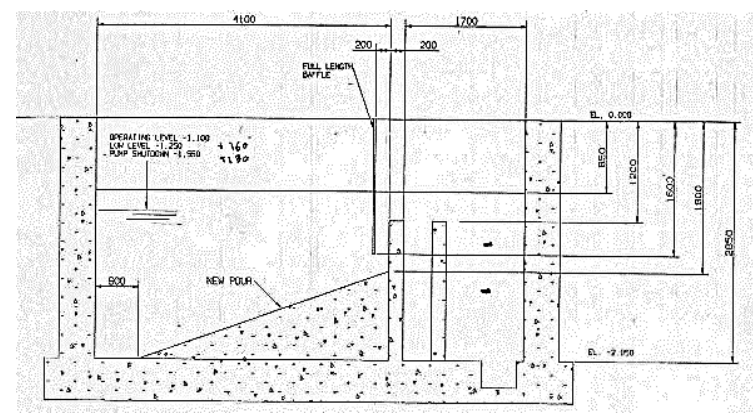

Gambar 4. Kolam Sump Pit SSCC 
Peningkatan endapan lumpur memicu timbulnya berbagai masalah antara lain frekuensi pembersihan sludge di SSCC sump yang semakin sering. Sensor level SSCC sump (pelampung) pada saat terjadi perubahan level air sering terganggu untuk naik/turun. Foot valve pyrites sluice pump sering stuck dan foot valve SSCC recirculation pump sering terjadi buntu. Untuk permasalahan tersebut peneliti akan menggunakan metode Jar test. Jar test bertujuan untuk memilih jenis koagulan yang cocok dan juga untuk memperkirakan dosis optimal yang diperlukan dalam menghilangkan partikel dalam air. Lokasi penempatan agitator disarankan berada diantara kompartemen sump pump dan pyrites sluice pump.

\section{Hasil dan Pembahasan}

Bagian ini adalah hasil penelitian. Perbedaan tampilan HMI memiliki kelebihan dan kekurangan tersendiri. Ketika operator menekan tombol remote, maka akan menjalankan salah satu pompa yang sudah di pilih untuk di running. Setelah pompa running, step selanjutnya adalah menutup inlet valve tramp iron dari pulverizer yang dipilih untuk di transport. Setelah mendapat feedback close, maka step selanjutnya akan menutup outlet ejector hopper yang dipilih. Setelah mendapat feedback close dari outlet ejector, maka step selanjutnya akan membuka inlet ejector hopper yang sudah dipilih untuk di transport. Gambar 5. Tampilan Monitor HMI Sebelum di Upgrade dan Gambar 6. Tampilan Monitor HMI Sesudah di Upgrade

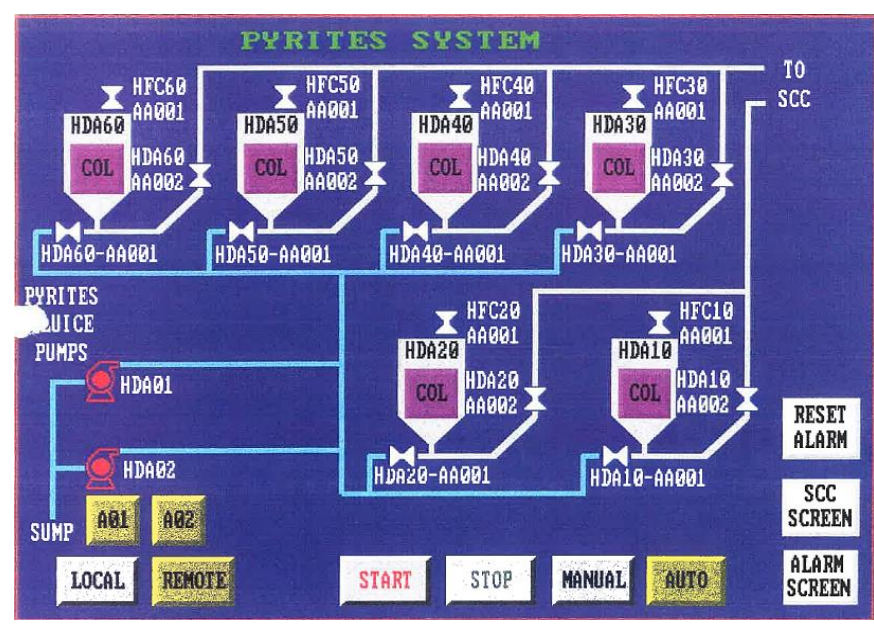

Gambar 5. Tampilan Monitor HMI Sebelum di

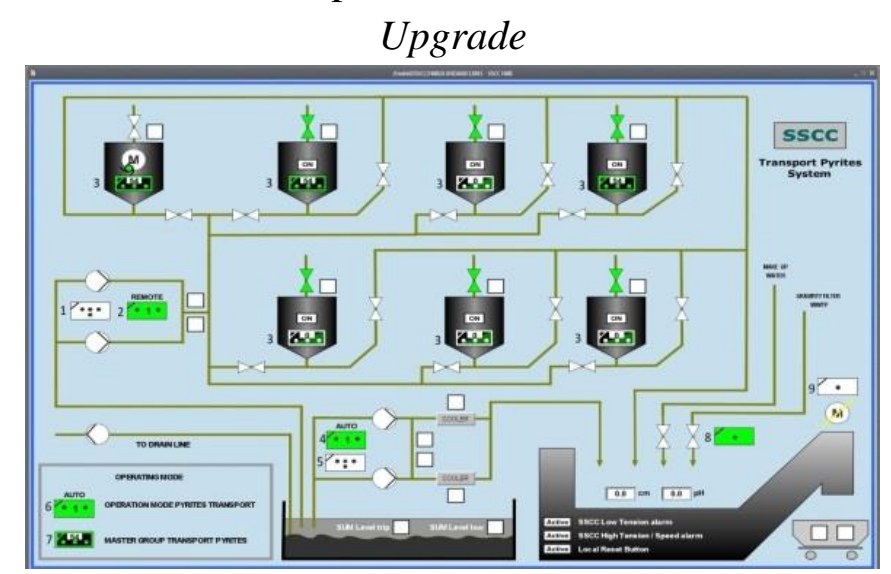

Gambar 6. Tampilan Monitor HMI Sesudah di Upgrade

Perbedaan tampilan HMI memiliki kelebihan dan kekurangan tersendiri. Ketika operator menekan tombol remote, maka akan menjalankan salah satu pompa yang sudah di pilih untuk di running. Setelah pompa running, step selanjutnya adalah menutup inlet valve tramp iron dari pulverizer yang dipilih untuk di transport. Setelah mendapat feedback close, maka step selanjutnya akan menutup outlet ejector hopper yang dipilih. Setelah mendapat feedback close dari outlet ejector, maka step selanjutnya akan membuka inlet ejector hopper yang sudah dipilih untuk di transport. Kemudian step selanjutnya proses flushing water pada hopper 
yang dipilih selama 5 menit. Setelah 5 menit berlalu, maka step selanjutnya adalah menutup inlet dan outlet ejector hopper yang dipilih, setelah mendapat feedback close akan melanjutkan pada step selanjutnya yaitu membuka inlet valve tramp iron dari pulverizer yang dipilih. Setelah mendapatkan feeedback open artinya proses transport pyrite pulverizer yang dipilih telah selesai, dan akan berpindah pada hopper pulverizer selanjutnya dengan proses berulang sampai semua hopper pulverizer telah selesai di transport, maka pompa akan berhenti dengan sendirinya

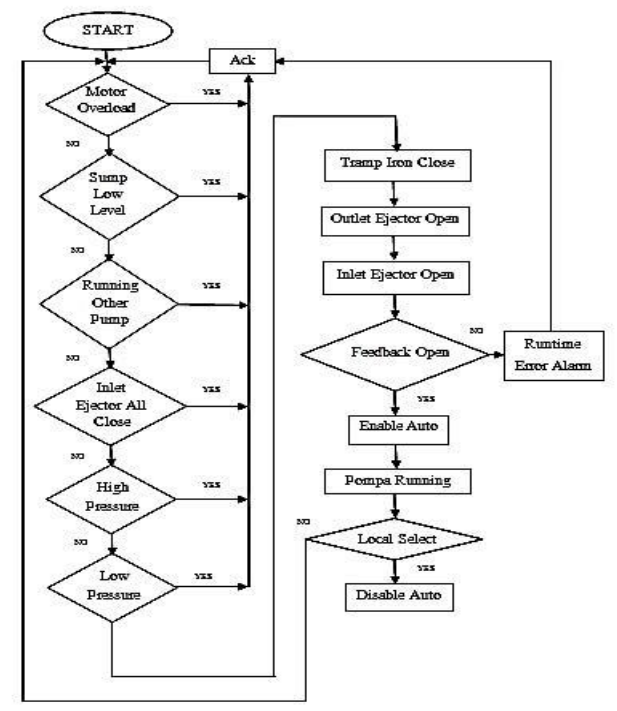

Gambar 7. Diagram Logic Start Pompa dan Sinyal Alarm Transport Pyrite Hopper

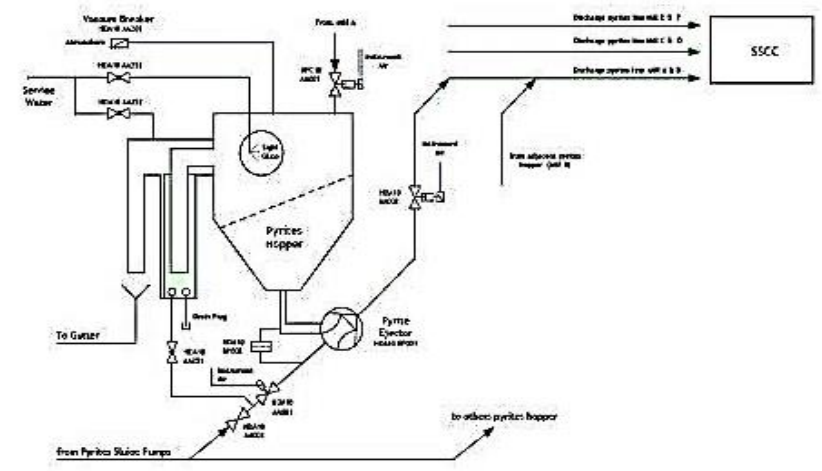

Gambar 8. Tampilan Hopper Pulverizer Sistem SSCC
Selama proses transport pyrite hopper berjalan akan saling terkoneksi feedback satu dengan yang lain untuk bisa melanjutkan step selanjutnya. Seperti motor running, inlet dan outlet ejector open close dan tramp iron pulverizer open close. Jika salah satu step tidak terpenuhi maka akan mengirimkan sinyal alarm pada tampilan HMI yang artinya operator harus mencari penyebab terjadinya sinyal alarm yang muncul. Proses kerja HMI sebelum dan sesudah di upgrade memiliki kelebihan dan kekurangan tersendiri. Ketika operator menekan tombol remote, maka akan menjalankan salah satu pompa yang sudah di pilih untuk di running.

Posisi Hardware Sistem SSCC meliputi tampilan panel local control system dengan supply tegangan 400 Volt, yang dioperasikan dengan beberapa PLC yang tersusun dalam 1 panel, yang telah di upgrade menggunakan siemens T3000.

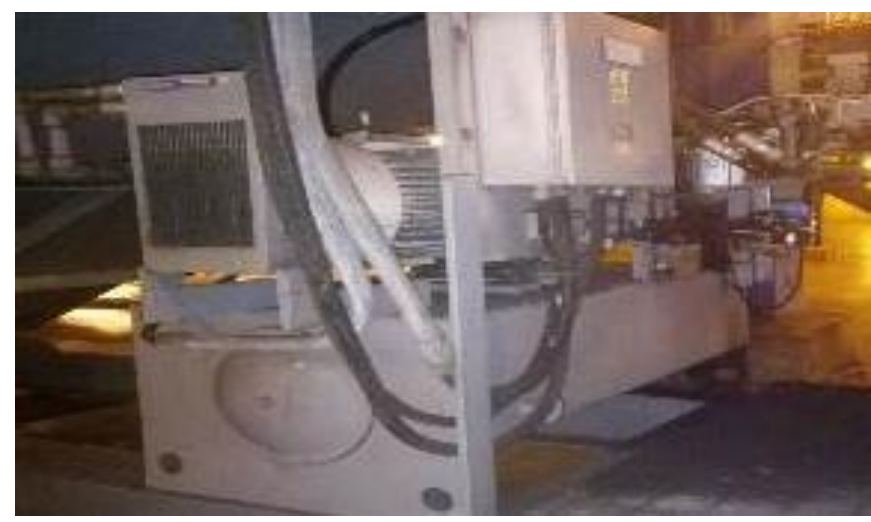

Gambar 9. MotorPenggerak Sistem SSCC

Sistem Kerja Motor Hydraulic SSCC merupakan penggerak utama pada sistem SSCC. Motor yang digunakan adalah jenis motor induksi 3 phasa dengan tegangan kerja 400 Volt, frekuensi $50 \mathrm{~Hz}$, dan daya $37 \mathrm{~kW}$. Motor ini memiliki range RPM 0 1470/min. Motor ini memiliki 4 pole dan cos phi 0.87 dengan arus 66 A. Pada gambar dibawah ini merupakan motor yang digunakan pada SSCC PLTU Paiton unit 50. 


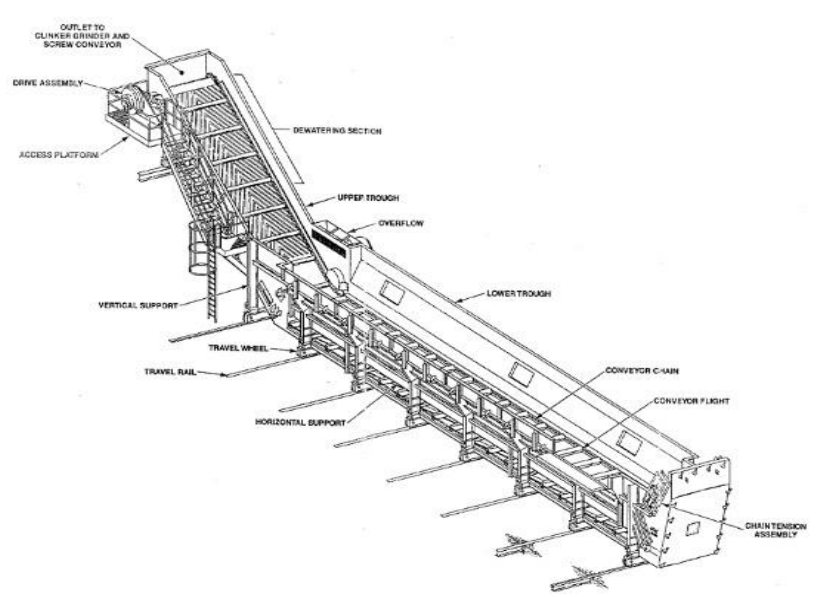

Gambar 10. Desain Sistem SSCC

Motor penggerak SSCC memutar conveyor melalui gearbox dengan forward speed sekitar 0,2 rpm, serta memindahkan slag yang jatuh dari boiler ke dalam container penampung yang selanjutnya akan dikirim ke ash lagoon / tempat penampungan bottom ash dan fly ash. Operator selalu memonitor setiap bagian SSCC sebagai parameter layak atau tidaknya komponen yang digunakan setiap harinya. Jika ada kerusakan atau komponen yang berpotensi akan rusak,maka operator akan segera membuat work order dan melapor kepada pihak maintenance untuk diperbaiki. Hal tersebut dilakukan demi menjaga kehandalan sistem kerja SSCC selama beroperasi.

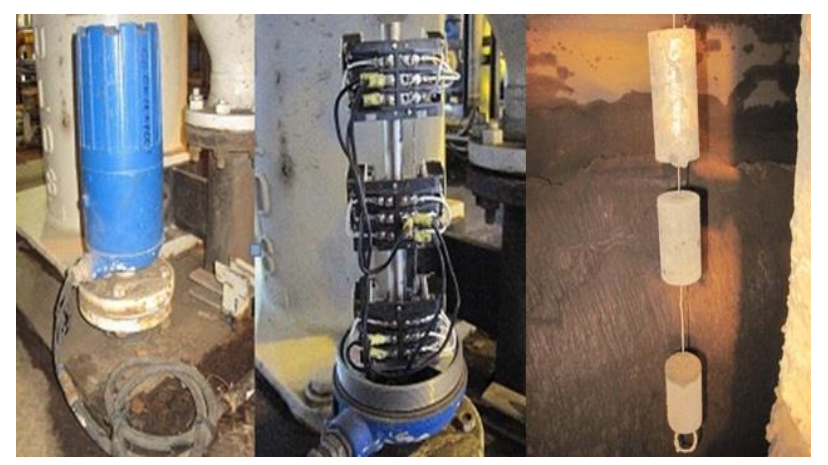

Gambar 11. Sensor Level Switch Transmitter
Pembahasan dari sensor level water sump SSCC menggunakan level switch transmitter ini digunakan sebelum di upgrade, dan mengalami beberapa permasalahan seperti adanya lumpur yang tersuspensi dari SSCC. Untuk menghilangkan lumpur yang tersuspensi dari SSCC sump pit dan mencegah lumpur masuk ke pyrites sluice pump \& recirculation pump suction, yakni dengan mengoperasikan SSCC sump pump sesuai dengan RTPM (Routine Test Preventive Maintenance). Untuk menjalankan RTPM SSCC sump pump setiap interval waktu 2 hari sekali setidaknya selama 5 menit dan dioperasikan secara manual. Selama RTPM dijalankan dan ketika SSCC sump pump dioperasikan secara manual, operator mengalami beberapa masalah, yakni SSCC sump pump bekerja secara terus menerus dan tidak dapat berhenti meskipun SSCC sump pit level sudah pada posisi Low Low Level. Permasalahan ini akan menyebabkan pompa pyrites sluice pump \& recirculation pump menjadi trip karena sudah pada level paling rendah dan permasalahan ini juga membahayakan SSCC sump pump itu sendiri karena bekerja tanpa adanya fluida yang akan dipompa.

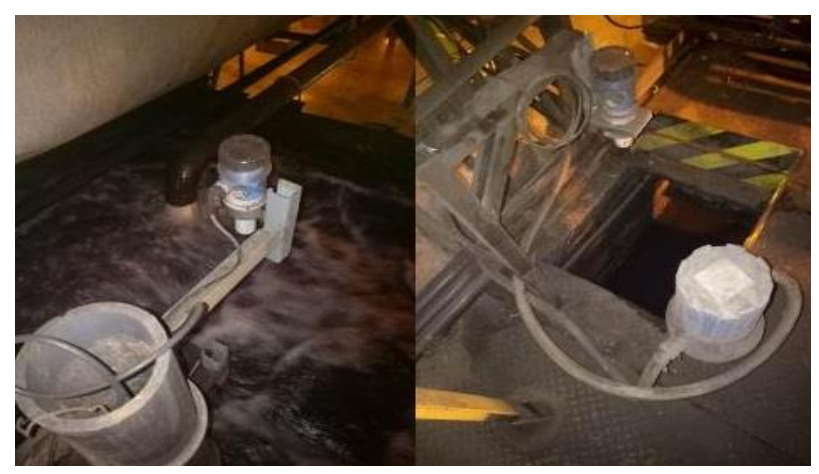

Gambar 12. Sensor Level Ultrasonic

Pembahasan dari sensor level Ultrasonic yaitu digunakan ketika sudah di upgrade dan dapat bekerja lebih baik dari pada sensor level switch 
transmitter yang digunakan sebelumnya, sehingga level air dalam SSCC sump pit dapat terkontrol sesuai dengan set point. Sensor ultrasonic adalah sebuah sensor yang berfungsi untuk mengubah besaran fisis menjadi besaran listrik dan sebaliknya. Cara kerja sensor ini didasarkan pada prinsip dari pantulan suatu gelombang suara sehingga dapat dipakai untuk menafsirkan eksistensi (jarak) suatu benda dengan frekuensi tertentu.
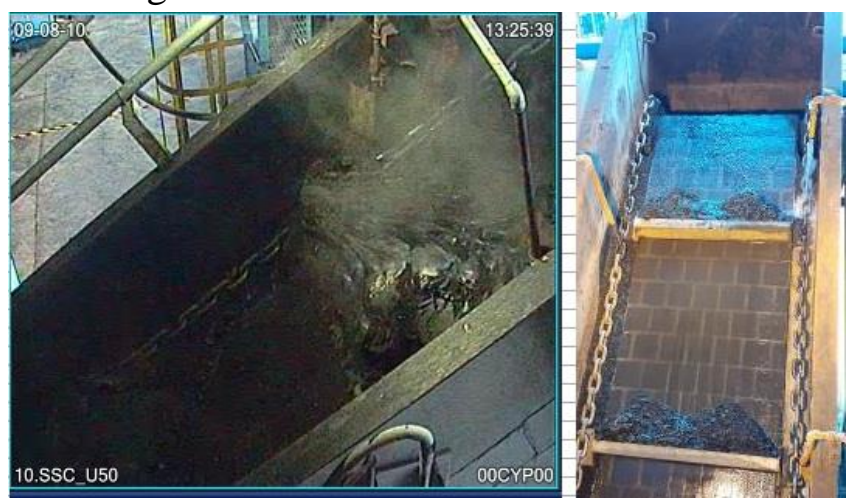

Gambar 13. Tampilan Perbedaan Slag Berdasarkan Volume

Pada sistem SSCC indikator pressure menjadi parameter yang perlu diperhatikan oleh operator untuk menjaga SSCC tetap dapat beroperasi. Parameter tersebut seperti filling system seal water harus pada posisi auto, SSCC hydraulic skid dan status pyrites sluice pump dalam posisi remote atau lokal. SSCC hydraulic skid meliputi forward speed reverse pada normal operasi termonitor 18 bar, reverse speed pressure termonitor 0 bar. Selain itu temperature dari lube oil tank normal operasi termonitor $46^{\circ} \mathrm{C}$, pembacaan $\mathrm{PH}$ meter masih dalam kisaran 8,51 dan parameter lain yang diperlukan yaitu spray washer for chain harus selalu tersedia untuk menjaga rantai SSCC tetap bisa beroperasi tanpa adanya slag yang mengganjal pada rantai SSCC. Operator akan memonitor kinerja SSCC selama beroperasi, jika terjadi alarm yang muncul maka harus segera merespon untuk mengetahui penyebabnya dan menyelesaikan permasalahan yang terjadi dilapangan. Munculnya indikator pressure SSCC yang tinggi akan mengakibatkan pulley SSCC terlepas dari rantai dan membuat SSCC berhenti serta memerlukan perbaikan dengan waktu yang cukup lama, maka dari itu indikator pressure SSCC perlu dimonitor dengan baik oleh operator dilapangan maupun di CCR.

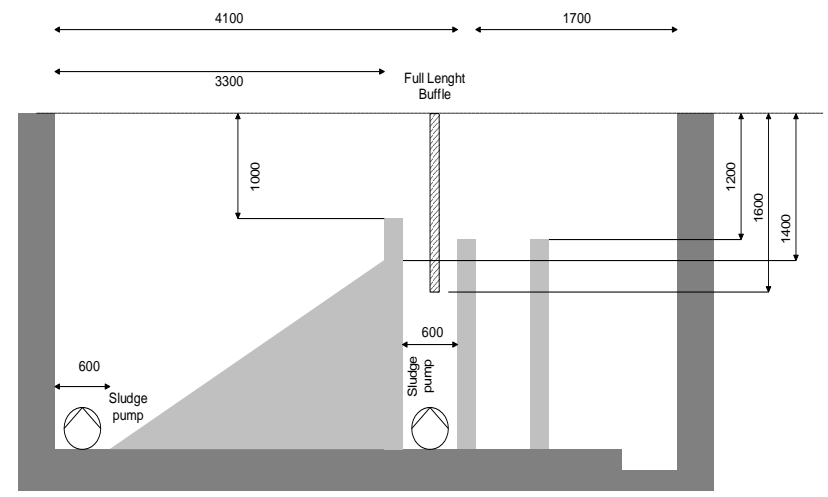

Gambar 14. Desain Kolam Sump Pit SSCC

Adanya usulan penambahan fasilitas untuk pencegahan peningkatan endapan lumpur pada kolam sump pit SSCC, yakni dengan menambah agitator. Seringkali lumpur (sludge/wet ash) tidak sepenuhnya mengendap di kompartemen sludge pump sehingga terikut ke kompartemen berikutnya dan mengendap. Volume endapan lumpur tersebut makin hari makin meningkat. Peningkatan endapan lumpur memicu timbulnya pelbagai masalah antara lain:

$\checkmark \quad$ Frekuensi pembersihan sludge di SSCC sump yang semakin sering.

$\checkmark \quad$ Sensor level SSCC sump (pelampung) pada saat terjadi perubahan level air sering terganggu untuk naik/turun.

$\checkmark \quad$ Footvalve pyrites sluice pump sering stuck. 
$\checkmark \quad$ Heat exchanger sscc recirculation pump sering terjadi sumbatan pada suction pump.

Salah satu ide yang akan diterapkan untuk mencegah sludge mengendap di kompartemen pyrite sluice pump dengan menambahkan agitator. Peneliti menggunakan metode Jar Tes yang telah dilakukan untuk mengetahui pada putaran (rpm) berapa endapan lumpur tersebut akan terurai sesuai dengan geometri jar. Jar tes dilakukan dengan prosedur sebagai berikut:

$\checkmark \quad$ Diisi dengan sejumlah sampel air ( \pm 2litres).

$\checkmark \quad$ Sludge yang berada pada sampel dibiarkan mengendap terlebih dahulu ( $\pm 24 \mathrm{jam})$.

$\checkmark$ Mempersiapkan percobaan dengan meletakan jar pada jar test equipment.

$\checkmark \quad$ Jar tes dilakukan dengan penambahan putaran (rpm) agitator hingga terbentuk uniform suspension.

$\checkmark \quad$ Mencatat putaran (rpm) agitator pada kondisi partial suspension, complete suspension, dan uniform suspension.

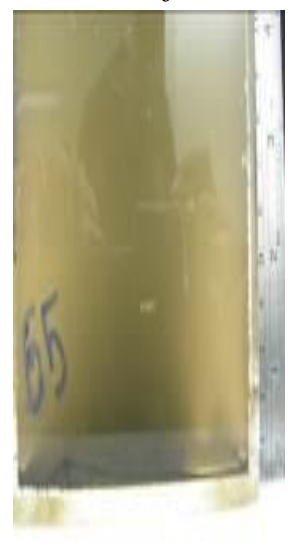

(a)

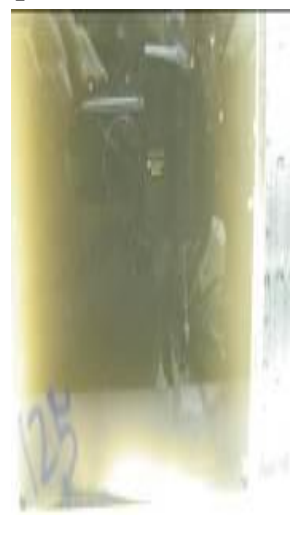

(b)

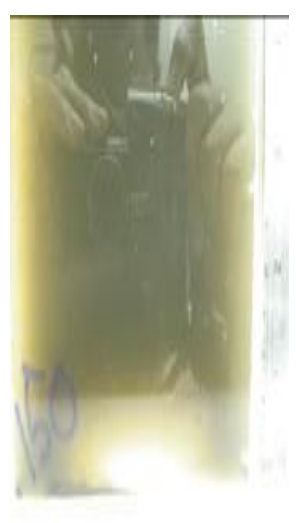

(c)
Gambar 15. Hasil Jar Test : (a) Partial suspension;

(b) Complete suspension; (c) Uniform suspension

Berdasarkan hasil jar tes diatas pada putaran agitator $65 \mathrm{rpm}$ telah terbentuk partial suspension ditandai dengan adanya endapan sludge di dasar jar yang mulai tersuspensi secara parsial. Pada putaran agitator $125 \mathrm{rpm}$ telah terbentuk complete suspension dimana semua endapan sludge di dasar jar mulai tersuspensi secara keseluruhan. Uniform suspension terbentuk pada putaran agitator $150 \mathrm{rpm}$ yang ditandai dengan terbentuknya solid-liquid systems.

Perencanaan awal desain agitator pada SSCC sump pit menggunakan data hasil jar tes dengan prinsip kesamaan geometri (geometric similarity) sebagai berikut:
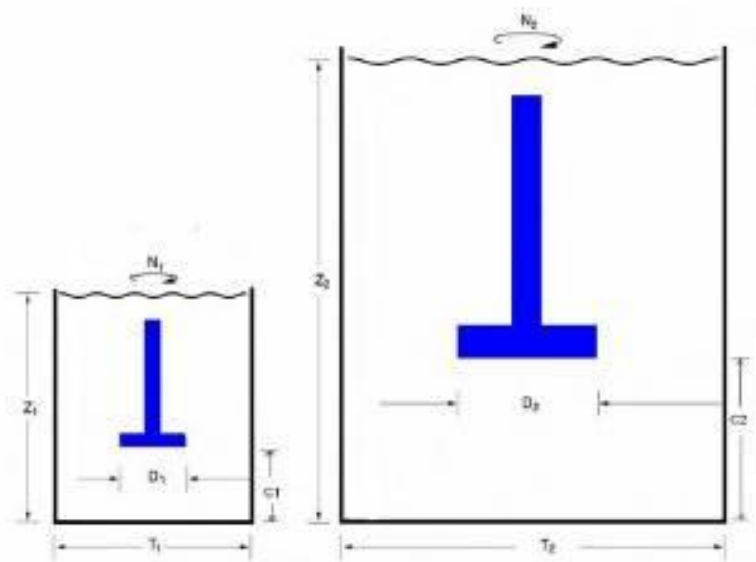

Gambar 16. Kesamaan Geometri

$R=\frac{D 2}{D 1}=\frac{C 2}{C 1}$

$R=\frac{D 2}{D 1}=\frac{1000 \mathrm{~mm}}{105 \mathrm{~mm}}=9.52$

Sehingga, rasio geometrinya adalah 9,52. Berdasarkan rasio geometri tersebut didapatkan:

$\mathrm{C} 2=\mathrm{R} \times \mathrm{C} 1=9,52 \times 35=333,2=333 \mathrm{~mm}$

Besarnya putaran agitator SSCC adalah

$$
\begin{aligned}
\mathrm{N} 2 & =\mathrm{N} 1 \times(1 / \mathrm{R})^{\mathrm{n}} \\
\mathrm{N} 2 & =150 \times(1 / 9,52)^{1} \\
& =15,75=16 \mathrm{rpm}
\end{aligned}
$$

Implementasi desain di lapangan meliputi pencampuran atau mixing suatu zat dapat 
dipengaruhi oleh proses pengadukan. Agar diperoleh pencampuran yang optimal perlu diperhatikan tipe pengaduk (agitator) yang digunakan. Pengaduk berfungsi untuk menggerakkan bahan (cair, cair ke padat, cair ke cair, cair ke gas, cair ke padat/gas) didalam bejana pengaduk. Pengaduk yang digunakan haruslah sesuai dengan tujuan pencampuran yang diinginkan. Agitator Jenis Baling-baling (Propeller) merupakan agitator / impeller aliran aksial berkecepatan tinggi untuk zat cair berviskositas rendah.
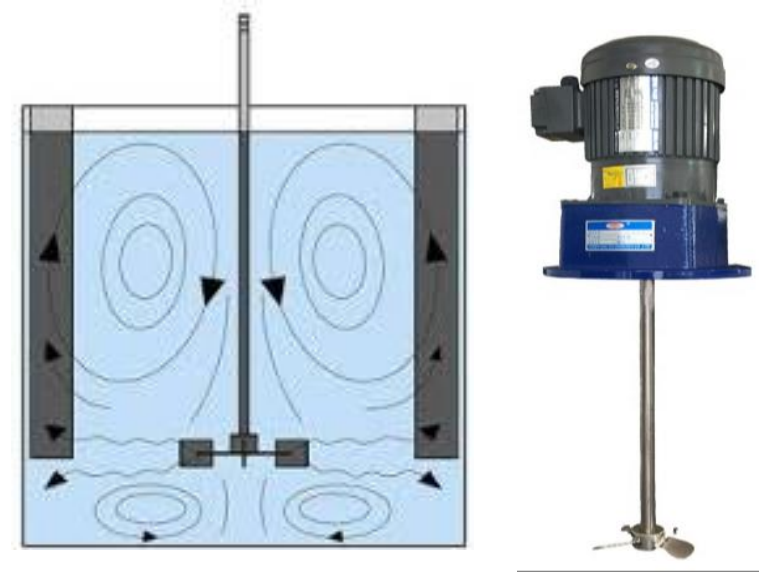

Gambar 17. Penempatan Agitator Jenis Propeller

Putaran minimal agitator yang disarankan adalah $16 \mathrm{rpm}$, dengan diameter agitator $1 \mathrm{~m}$ dan jarak dasar kolam dengan agitator $0,3 \mathrm{~m}$. Lokasi penempatan agitator disarankan berada diantara kompartemen sump pump dan pyrites sluice pump.

\section{KESIMPULAN}

Dari hasil penelitian diambil kesimpulan bahwa

1. Berdasarkan sistem kerja yang diterapkan pada salah satu bagian terpenting dari PLTU yakni sistem SSCC yang sebelumnya dioperasikan secara manual, kemudian diubah menjadi auto / lebih mudah dioperasikan menciptakan sistem kerja yang efektif dan efisien selama unit beroperasi, sehingga memudahkan pekerjaan dari operator di lapangan, serta meningkatkan kualitas equipment yang berada di lokal.

2. Penggunaan sistem proteksi merupakan langkah awal dalam menangani sebuah kejadian di lapangan serta untuk mengamankan equipment yang lain. Untuk itu pentingnya mengetahui macam-macam proteksi dan perawatan yang dilakukan dalam mempertahankan kehandalan dari sistem SSCC sangat diperhatikan.

3. Perkembangan usulan / ide yang dapat membangun sistem kerja menjadi lebih baik, sangat diperlukan di unit pembangkit PLTU dengan menggunakan berbagai metode yang tepat pada sistem pembangkit PLTU.

\section{DAFTAR PUSTAKA}

[1] F. Basim Ismail, E. Why Siew Kuan, and M. Shakir Nasif, "Development and implementation of bottom ash crushing system in Submerged Scrapper Conveyor (SSC) for Coal-fired Power Plant," MATEC Web Conf., vol. 131, pp. 1-6, 2017.

[2] B. A. Mir and A. Malik, "Studies on the Mechanical Behavior of Bottom Ash for a Sustainable Environment," Int. J. Civ. Environ. Eng., vol. 11, no. 7, pp. 857-863, 2017.

[3] Broadcom, "Hardware Design Guidelines Design Guide," 2019. [8] C. T. Sdn, "Product User's Manual-HCSR04 Ultrasonic Sensor User's Manual Product User's Manual-HCSR04 Ultrasonic Sensor Index," no. May, pp. 1-10, 2013. 
[4] Industrial System, General Electric. 2007.

Electrical

and

Electronics

Engineers, Drive Basic System. USA : s.n., 2007. Inc.,1978.

[5] Corporation, Termokimik. 1993. Ash Handling Manual Operation Part 1. Probolinggo: s.n., 1993.

[6] IEEE Std. C57.12.80-1978, IEEE Standard Terminology For Power and Distribution Transformers. New York : Institute of 